\title{
Malignant Diseases of the Paranasal Sinuses in Nigeria
}

\author{
By S. P. Singh and F. D. Martixson (Ibadan, Nigeria)
}

THE wide variations both geographic and ethnic, in the incidence and pattern of malignant diseases of the paranasal sinuses have prompted theories that racial and environmental factors may play a part in their aetiology (Keen, I955; Clifford, I96I; Marsden, 1958). In developing countries the recorded incidence may be influenced to a variable extent by the availability and accessibility of medical services, as well as by the attitude of the population to "non-traditional" medical practice. Other factors such as the absence of universal registration of births and deaths, and the doubtful accuracy of some census figures, add to the problems involved in studying the incidence of the disease. This report is concerned with a study of the pattern of malignant disease of the paranasal sinuses in Nigeria as it is reflected in the records of the Ear, Nose and Throat Unit of the University College Hospital, Ibadan. Although the Burkitt tumour involving the upper jaw is not infrequently seen in the Ear, Nose and Throat Unit, it has not been included in this review.

\section{Material}

The cases included in this report were all seen in the E.N.T. Department of the University College Hospital, Ibadan, from I960 to I966 inclusive. They came from all parts of Nigeria but mostly from the Western State in which this hospital is situated. Since the indigenous population of this region is mainly Yoruba, a large percentage of patients, as might be expected, belong to this tribal group. For this reason, and because the figures do not represent the total incidence in the whole country, no attempt will be made to classify the patients according to their ethnic or regional areas of origin.

\section{Incidence}

In the period under review, 5,989 new patients were seen in the ear, nose and throat unit and of these, 136 or $2 \cdot 2$ per cent. had malignant disease of the paranasal sinuses. Their ages ranged from 3 months (Fig. I) to 69 years with a maximum incidence in the fourth to sixth decades (Table I). The males outnumber the females by approximately $5: 3$. 


\section{S. P. Singh and F. D. Martinson}

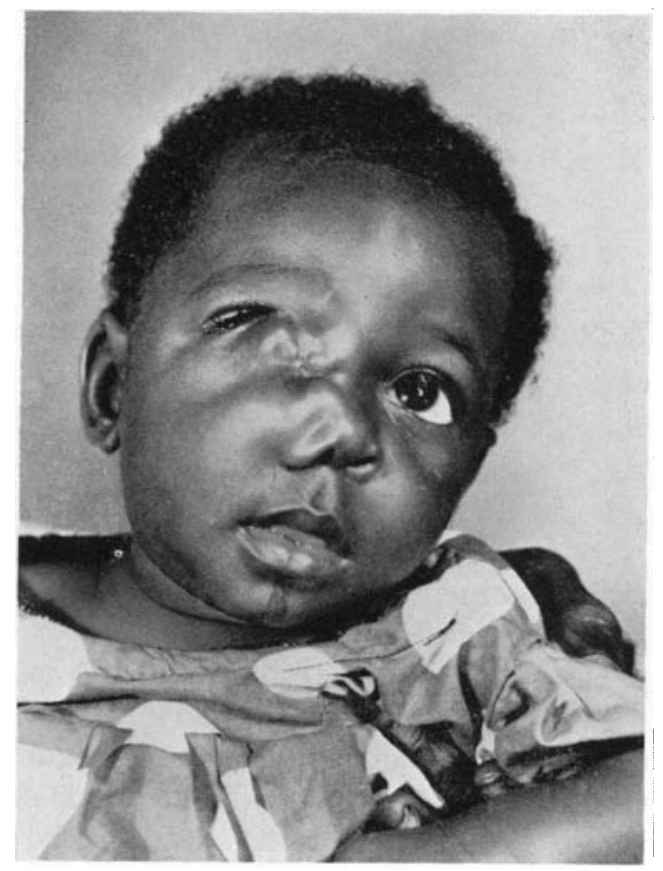

FIG. I.

Child aged 3 months with tumour of ethmoidal region. Diagnosis: undifferentiated round cell sarcoma.

\section{Sites of Origin}

\section{Clinical Features}

The commonest site of origin was the maxillary antrum ( 48 per cent.) and next in frequency the ethmoidal sinuses ( 36 per cent.). $14 \cdot 6$ per cent. of the cases are classified in Table II as antro-ethmoidal, because it was not possible to determine, when the patients first presented for treatment, in which of these two sinuses the tumours may have originated owing to their very extensive nature. Only two cases or I 44 per cent. of the total were found definitely to have originated from the frontal sinuses.

\section{Signs and Symptoms}

Table II shows the various symptoms complained of and the frequency of their occurrence. The commonest presentation of the antral tumours

TABLE I.

AgE AN D SEX INCIDENCE.

\begin{tabular}{|c|c|c|c|c|c|c|c|c|c|}
\hline Sex & $o-5$ & $6-10$ & I I-20 & $21-30$ & $3 I-40$ & $4 \mathrm{I}-5^{\circ}$ & $5^{1-60}$ & Over 6o & Total \\
\hline $\begin{array}{l}\mathbf{M} \\
\mathbf{F}\end{array}$ & $\begin{array}{l}2 \\
2\end{array}$ & $\begin{array}{l}7 \\
2\end{array}$ & $\begin{array}{l}\text { I } \\
4\end{array}$ & $\begin{array}{l}6 \\
6\end{array}$ & $\begin{array}{l}\text { I I } \\
\text { I } 4\end{array}$ & $\begin{array}{l}22 \\
\mathrm{I} 2\end{array}$ & $\begin{array}{r}22 \\
6\end{array}$ & $\begin{array}{r}15 \\
4\end{array}$ & $\begin{array}{l}86 \\
50\end{array}$ \\
\hline Total & 4 & 9 & 5 & I 2 & 25 & 34 & 28 & I9 & $13^{6}$ \\
\hline
\end{tabular}




\section{Malignant Diseases of the Paranasal Sinuses in Nigeria}

TABLE II.

Main Presentation and Symptoms.

\begin{tabular}{l|c|c}
\hline & $\begin{array}{c}\text { Number of } \\
\text { Patients }\end{array}$ & Percentage \\
\hline Swelling of face & 97 & $7 \mathrm{I} \cdot 3$ \\
Visible intranasal tumour & 74 & $54 \cdot 4$ \\
Local pain/headache & 66 & $48 \cdot 5$ \\
Proptosis & $5 \mathrm{I}$ & $37 \cdot 5$ \\
Epistaxis & 53 & $38 \cdot 9$ \\
Bulging of palate & 43 & $3 \mathrm{I} \cdot 6$ \\
Complete nasal obstruction & I Io & $80 \cdot 9$ \\
\hline
\end{tabular}

was as a swelling over the cheek (Fig. 2) or in the palate, often with ulceration through the latter site, and nasal obstruction. The last mentioned, even when obviously present, was often not complained of especially when it was incomplete or purely unilateral. Proptosis in varying degrees of severity was commonest in lesions involving the ethmoids (Fig. 3), but in ten of the fifty-one patients with this symptom the tumours were purely antral. Seven patients had complete loss of vision in the affected eye and four had bilateral proptosis.

\section{Duration of Symptoms}

As far as could be ascertained from the histories given, this ranged from I week to 6 years (Table III) but many lesions said to have been

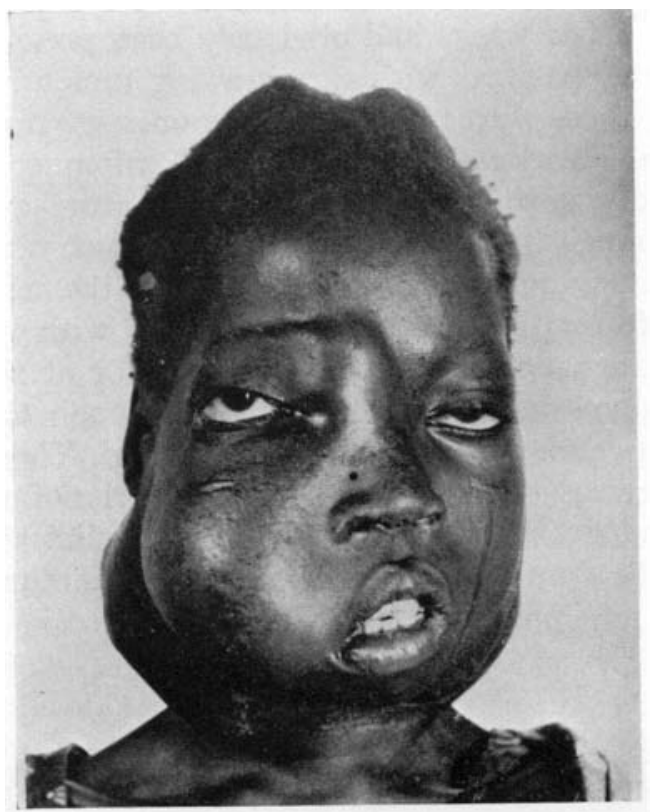

FIG. 2.

Girl aged i 8 with anaplastic carcinoma of maxilla, secondary glands in neck and swelling of cheek.

Reproduced by permission of the Editor of the British Journal of Cancer.

$24 \mathrm{I}$ 


\section{S. P. Singh and F. D. Martinson}

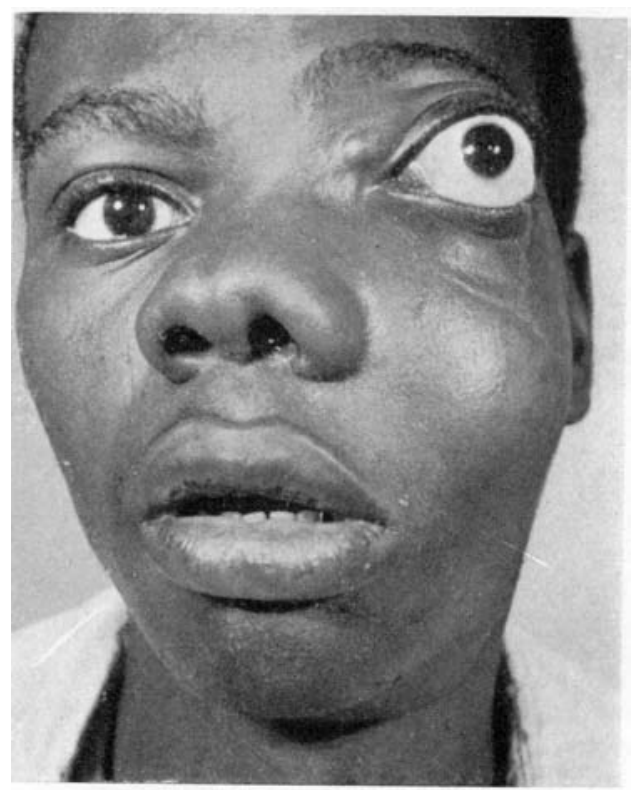

FIG. 3 .

Boy of 18 years with antro-ethmoidal tumour. Proptosed left eyeris completely blind.

noticed for only a few weeks had obviously been present for very much longer. In general, patients with slow-growing tumours tend to present much later than those with rapidly growing ones, even when proptosis is an early feature. This latter symptom is not infrequently ignored until vision is markedly impaired. Pain is a late feature and is apparently seldom severe enough to cause concern, a fact which may partly explain why, in spite of its frequent occurrence (Table II) the majority of patients arrive rather late for treatment. In three cases with long histories the possibility of malignancy having developed in, or at the site of simple inflammatory polyps has been considered, although the question of a missed diagnosis cannot be altogether discounted. These three patients had, during the course of their 4 to 6 years' histories of nasal obstruction, been operated on for removal of what were thought clinically and diagnosed histologically to be simple polyps from the antrum or ethmoid in which the malignancy was now present.

TABLE III.

DURATION OF SYMPTOMS.

\begin{tabular}{|c|c|c|c|c|c|c|c|c|c|c|c|c|c|c|c|c|c|c|}
\hline \multirow{2}{*}{ Duration } & \multicolumn{4}{|c|}{ Weeks } & \multicolumn{10}{|c|}{ Months } & \multicolumn{4}{|c|}{ Years } \\
\hline & I & 2 & 3 & 4 & 2 & 3 & 4 & 5 & 6 & 7 & 8 & 9 & 10 & I I & I & 2 & 3 & $45+$ \\
\hline Number of patients & 3 & 5 & 5 & I I & 12 & 20 & I 5 & 6 & I 8 & 4 & 3 & 3 & 2 & 2 & 16 & $\mathrm{I}$ & 2 & 5 \\
\hline
\end{tabular}




\section{Malignant Diseases of the Paranasal Sinuses in Nigeria}

\section{Pathology}

Histopathological confirmation of malignancy was obtained in all but seventeen cases who for various reasons either refused admission or did not keep their appointments for biopsy. Diagnosis in these cases was based on clinical and radiological findings only. All biopsies were examined by light microscopy of formalin-fixed specimens, but in some cases particularly when the diagnosis was in doubt they were examined by tissue culture. As shown in Table IV, 64 per cent. of all the tumours were carcinomas,

TABLE IV

Site and Histopathology.

\begin{tabular}{|c|c|c|c|c|c|c|c|c|c|c|c|c|}
\hline \multirow{2}{*}{ Diagnosis } & \multicolumn{2}{|c|}{ Antrum } & \multicolumn{2}{|c|}{ Ethmoid } & \multicolumn{2}{|c|}{$\begin{array}{l}\text { Antro- } \\
\text { Ethmoid }\end{array}$} & \multicolumn{2}{|c|}{ Frontal } & \multicolumn{3}{|c|}{ Total } & \multirow[t]{2}{*}{$\begin{array}{l}\text { Percent } \\
\text { age }\end{array}$} \\
\hline & $\mathrm{M}$ & $F$ & M & $\mathrm{F}$ & $M$ & $\mathrm{~F}$ & $\mathbf{M}$ & $F$ & $\mathrm{M}$ & $\mathrm{F}$ & & \\
\hline I. Transit cell carc. & & & 3 & I & I & & $\mathbf{I}$ & & 5 & I & 6 & $4 \cdot 4$ \\
\hline 2. Squamous carcinoma & I 5 & I4 & 9 & 4 & 6 & 4 & & $\mathbf{I}$ & 30 & 23 & 53 & $39 \cdot 8$ \\
\hline 3. Adenocarcinoma & 2 & & I I & 5 & 2 & I & & & I 5 & 6 & $2 \mathrm{I}$ & I $5 \cdot 5$ \\
\hline 4. Papillary carcinoma & & $\mathbf{I}$ & & & & & & & & I & I & 0.7 \\
\hline $\begin{array}{l}\text { 5. Malignant salivary } \\
\text { tumour }\end{array}$ & 2 & 3 & & & & & & & 2 & 3 & 5 & 2.6 \\
\hline 6. Fibrosarcoma & $\mathrm{I}$ & $\begin{array}{l}3 \\
\mathbf{I}\end{array}$ & & I & I & & & & 2 & $\begin{array}{l}3 \\
2\end{array}$ & $\begin{array}{l}5 \\
4\end{array}$ & $2 \cdot 9$ \\
\hline 7. Retic. cell sarcoma & 2 & & & I & I & & & & 3 & I & 4 & $2 \cdot 9$ \\
\hline 8. Lymphosarcoma & 4 & 2 & 4 & & I & & & & 9 & 2 & II & $8 \cdot \mathbf{I}$ \\
\hline 9. Undifft. sarcoma & & 2 & & & & & & & & 2 & 2 & $\mathrm{I} \cdot 4$ \\
\hline 1o. Plasmacytoma & & & 2 & 2 & & & & & 2 & 2 & 4 & $2 \cdot 9$ \\
\hline II. Adamantinoma & $\mathbf{I}$ & & & & & & & & $\mathbf{I}$ & & I & 0.7 \\
\hline I2. Rhabdomyosarcoma & 2 & & & 2 & & & & & 2 & 2 & 4 & $2 \cdot 9$ \\
\hline I3. Neurogenic tumour & $\mathbf{I}$ & & & & & & & & I & & I & $0 \cdot 7$ \\
\hline I4. Wegner lethal & & $\mathrm{I}$ & & & & & & & & $T$ & & \\
\hline $\begin{array}{l}\text { granuloma } \\
\text { I5. Malignant reticulosis }\end{array}$ & & & & I & & & & & & $\begin{array}{l}1 \\
I\end{array}$ & $\begin{array}{l}1 \\
\mathbf{I}\end{array}$ & $\begin{array}{l}0 \cdot 7 \\
0 \cdot 7\end{array}$ \\
\hline I6. Clinical & 9 & 2 & 3 & & 2 & $\mathbf{I}$ & & & $I_{4}$ & 3 & I 7 & I $3 \cdot 2$ \\
\hline Total & 39 & 26 & 32 & I 7 & I 4 & 6 & I & $\mathbf{I}$ & 86 & 50 & 136 & \\
\hline Percentage & & & & & & & & & & & $6 \cdot 7$ & \\
\hline
\end{tabular}

40 per cent. being squamous carcinomas in various stages of differentiation, including the controversial lymphoepitheliomas. Adenocarcinomas which occurred two-and-a-half times as frequently in males as in females were found most often in the ethmoids and formed 15 per cent. of all the tumours seen. The five malignant salivary tumours recorded were all in the antrum. Among the less common soft tissue tumours were the plasmacytomas, rhabdomyosarcomas and one neurogenic tumour whose exact histopathology was difficult to decide.

Antral tumours often spread beyond the boundaries of the sinus even before the cavity is filled. Extension occurs into the oral cavity, soft tissues of the cheek, the opposite nasal airway, the nasopharynx or the orbital cavity. Three of the cases of proptosis were found to be due to infection rather than to macroscopic involvement of the orbital tissues. The base of 


\section{S. P. Singh and F. D. Martinson}

the skull was not infrequently eroded and in three such cases there was extensive invasion of the anterior or middle cranial fossa though the clinical features at the time did not suggest intracranial spread. Forty-six patients were found to have cervical glandular metastases (Table V), and of these twenty-nine (63 per cent.) had carcinomas, twenty-two of which were of the squamous variety and five were adenocarcinomas. Just over 25 per cent. of the glandular metastases originated in sarcomas. On the whole, metastases were seen most often when the primary tumour had ulcerated through the palate and usually very late in the course of the disease.

TABLE $V$.

Metastases.

\begin{tabular}{l|r|l}
\hline No. without metastases & 90 & \\
\hline Cervical glandular & 39 & Unilateral \\
metastases & 7 & Bilateral \\
\hline & 4 & Lungs \\
Other metastases & 2 & Vertebra \\
& I & Mandible \\
& I & Skull \\
\hline
\end{tabular}

Distant metastases were detected in eight cases. In one, an antral tumour, metastases were demonstrated radiologically in the mandible and the eighth dorsal vertebra (Fig. 4). In another, an ethmoidal tumour diagnosed histologically as an adenocarcinoma there were "multiple osteolytic lesions in the skull' (Fig. 5).

\section{Treatment}

As radiotherapy is not available, treatment has been by radical or palliative surgery, chemotherapy alone or in combination with surgery, or merely by supportive therapy when active intervention is considered inadvisable. This limitation of facilities for treatment has made it necessary to extend the criteria of operability to include those cases for whom there is the faintest chance of increasing the period of survival without prolonging misery and suffering, the only limiting factor in such cases often being the patient's ability to withstand surgical trauma. In most cases when extensive surgery is necessary, the question of availability of facilities for making suitable prostheses may arise, and occasionally there may be stubborn objection on traditional or religious grounds, to certain surgical procedures such as the removal of an eye.

Chemotherapeutic management in this series consists of the administration of intravenous endoxan or intra-arterial nitrogen mustard. The former is given as daily injections of the drug in doses of Io-I5 mg. per kg. of body weight for 5 to 7 days. The latter involves the passage of a Seldinger catheter up the femoral artery into the arch of the aorta or the common 


\section{Malignant Diseases of the Paranasal Sinuses in Nigeria}

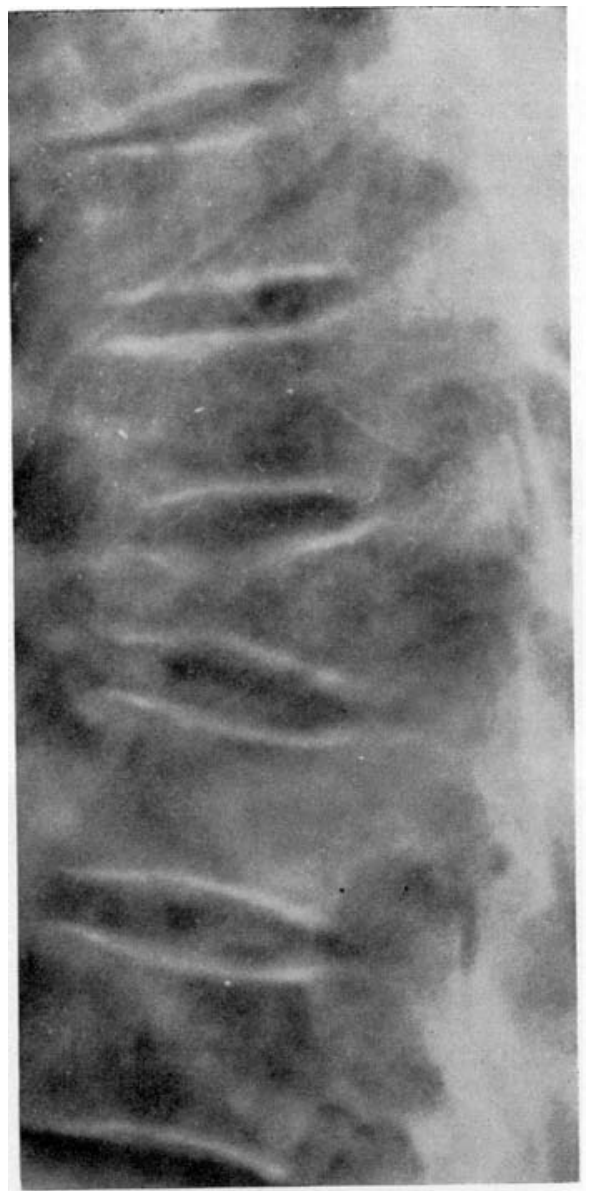

FIG, 4.

Radiograph of spine showing collapse of VIIIth dorsal vertebra due to metastasis from carcinoma of antrum.

carotid under radiographic control and the injection through this of I-I $5 \mathrm{mg}$. per kg. of nitrogen mustard. The amount given into the carotid artery is about one-fifth of the calculated body dosage which would normally be given into the arch of the aorta. Methotrexate has also been used when available, but as with the other two, success has been variable particularly with tumours of epithelial origin.

Since a large number of patients fail to attend for follow-up whether improvement is initially good or negligible, it is difficult to evaluate the results of treatment or estimate the survival in the whole series with or without treatment.

Of the 136 patients, forty-five were considered too far advanced for anything but supportive therapy. These included twenty-five antral, 


\section{S. P. Singh and F. D. Martinson}

TABLE VI.

Histopathology of Tumours Producing Metastases.

\begin{tabular}{lrrr}
\hline Squamous carcinoma & 22 & 4 Bilateral \\
Adenocarcinoma & 5 & \\
Reticulum cell sarcoma & 2 & I Bilateral \\
Fibrosarcoma & 3 & \\
Lymphosarcoma & 5 & \\
No biopsy & 5 & \\
Mixed salivary & 2 & \\
Rhabdomyosarcoma & 2 & \\
\hline
\end{tabular}

twelve ethmoidal and eight antro-ethmoidal lesions. In some advanced cases "extended biopsies" have helped at least to diminish pain, stop epistaxis and produce some psychological relief though often shortlived.

The longest average survival period was noted in patients with ethmoidal tumours (Table VII), but this may be because patients in this group tended to have symptoms early and therefore presented earlier than others for treatment. The two patients with frontal sinus tumours survived only a few months.

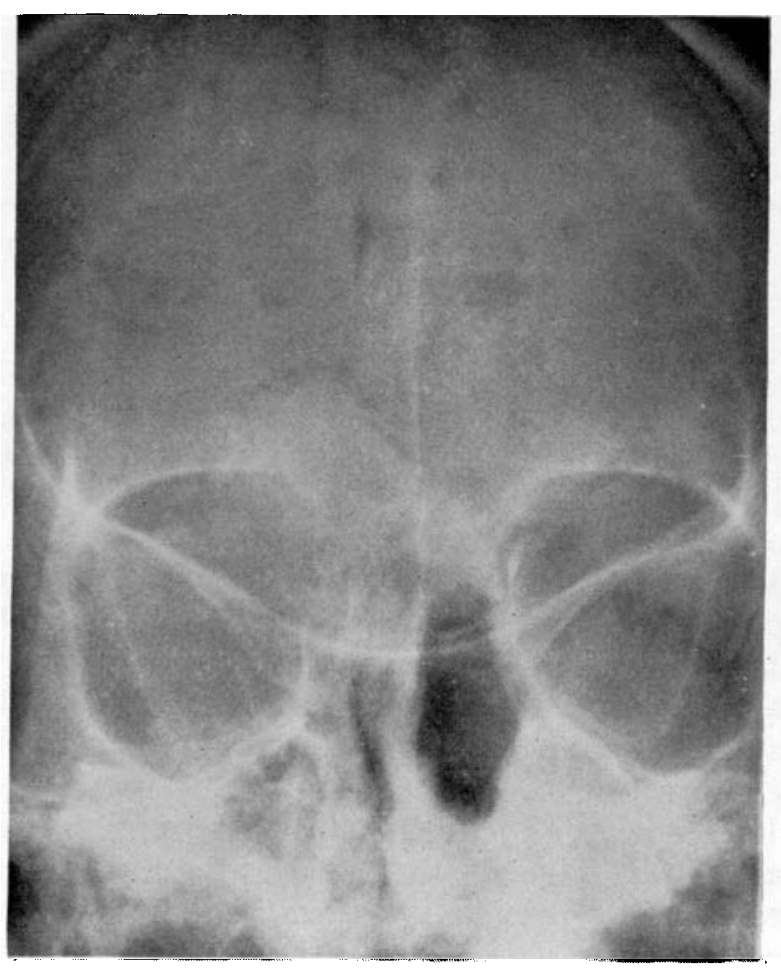

FIG. 5 .

Adenocarcinoma of ethmoids - Radiograph showing multiple osteolytic deposits in skull. 246 


\section{Malignant Diseases of the Paranasal Sinuses in Nigeria}

TABLE VII.

Survival of Patients Followed-up for at least I year.

\begin{tabular}{|c|c|c|c|c|c|c|}
\hline \multirow{2}{*}{ Site } & \multirow{2}{*}{$\begin{array}{c}\text { Number } \\
\text { Followed-up }\end{array}$} & \multicolumn{5}{|c|}{ Survival (Years) } \\
\hline & & I & 2 & 3 & 4 & 5 \\
\hline $\begin{array}{l}\text { Ethmoids } \\
\text { Antrum } \\
\text { Antro-ethmoid }\end{array}$ & $\begin{array}{l}32 \\
39 \\
\text { I } 5\end{array}$ & $\begin{array}{r}15 \\
7 \\
3\end{array}$ & $\begin{array}{l}9 \\
4 \\
0\end{array}$ & $\begin{array}{l}8 \\
4 \\
0\end{array}$ & $\begin{array}{l}3 \\
3 \\
0\end{array}$ & $\begin{array}{l}2 \\
2 \\
0\end{array}$ \\
\hline All Sites & 86 & 25 & I 3 & 12 & 6 & 4 \\
\hline
\end{tabular}

Among the few long survivors (Table VIII) are one patient with fibrosarcoma and another with a transitional cell tumour both of whom were treated by surgery only and are still alive 7 years after their first visit. On the other hand, no patients with squamous carcinomas survived as long as three years. The survival periods of patients who received any form of treatment and whom it has been possible to follow up for a year or more are shown in Table VII. Approximately I4 per cent. of these survived at least 3 years and 4.6 per cent. have survived 5 years or more. On the whole the overall survival rates compare unfavourably with European reports such as those of Osborn and Winston (I96I) or Macbeth (I965).

TABLE VIII.

Histopathology of Long Survival Cases

\begin{tabular}{l|c|c} 
& No. Alive at & No. Alive at \\
& 3 Years & 5 Years \\
\hline Adenocarcinoma & 2 & 0 \\
Cylindroma & 2 & $I^{*}$ \\
Lymphosarcoma & 1 & $I^{*}$ \\
Fibrosarcoma & 2 & $\mathrm{I}^{*}$ \\
M.S.T. & $\mathrm{I}$ & $\mathrm{o}$ \\
Trans. cell carcinoma & $2^{*}$ & $\mathrm{I}^{*}$ \\
Extramedullary plasmacytoma & $2^{*}$ & \\
\hline
\end{tabular}

* Still being followed up.

\section{Comment}

Cancer of the paranasal sinuses as seen in this hospital reflects the pattern of the disease as it occurs in Nigeria, though such factors as distance, local social problems and finance as well as the limited medical facilities and the absence of universal compulsory registration of births and deaths make it impossible to say at present what proportion of the total incidence is represented here. According to Edington and Maclean (1965) the incidence of cancer of the nose and paranasal sinuses is $\mathrm{I} \cdot 9$ per cent. of all the cancers recorded in the pathology department of the University College Hospital, Ibadan. By comparison, cancer in the same region is said to be about $0 \cdot 3$ per cent. of all cancers in England (Macbeth, 1965) while in Kenya it is I. 2 per cent. (Linsell and Martyn, I962); in Salisbury 0.9 per cent. (Ross, 1967) and in Uganda 0.8 per cent. (Dodge, I965). The high 


\section{S. P. Singh and F. D. Martinson}

relative incidence here may be due to the lower total incidence of all cancers (Edington and Maclean, 1965).

Various reasons have been suggested to explain why cancer of the paranasal sinuses has not been seen in as old an age group as it has been in Europe (Edington and Maclean, I965). Similar theories may be offered to explain also why, as in other African countries (Shapiro et al., I955), the peak incidence here occurs a decade or more earlier than reports from Europe (Macbeth, I965; Osborn and Winston, I96I; Clemmesen, r95I) suggest. As regards sex incidence, there is a preponderance of male over female cases but it is not possible to say to what extent, if any, the higher ratio of male to female hospital attendances, which in the E.N.T. department is approximately $5: 3$ may be responsible for the recorded difference. In Kenya (Clifford, I961), and in Salisbury (Ross, I967), the male cases exceeded the females by $5: 2$. Even higher ratios of $4 \cdot 4:$ I and $4 \cdot 7: \mathrm{I}$ were recorded in South African Bantus by Shapiro et al. (1955) and Keen et al. (1955) respectively. Although the male incidence of this disease is usually expected to be higher than that of the female, it is interesting to see that in Ringertz's series (1938) there was a higher female incidence. In Peru also, Salem et al. (Ig63) reported a male incidence of only $47 \cdot 4$ per cent. of the total and in Jamaica, Bras et al. (1965) showed that the females exceeded the males by $2: \mathrm{I}$ in a small series of fifteen cases.

It was observed earlier that 64 per cent. of all the tumours were varieties of carcinomas. This is low compared with other reports in Africa such as that of Shapiro et al. (1955) who found 85 per cent. in the Bantu and that of Linsell and Martyn (I962) who reported 80 per cent.

Theoretically treatment of patients without metastases should have a reasonable chance of success, but since malignant adenopathy is usually late in appearing and patients rarely present early for treatment, many of the cases seen are inoperable even before glandular metastases are evident. As has been noted by Capps (I950), Mattick and Streuter (I954), Mel'nikov (1960) and Barbosa (I96I), the tendency not to present early for treatment seems universal. Delay in seeking medical aid here and probably in other developing countries cannot be blamed solely on the silent nature of these tumours in their early stages, since patients arrive usually when pain is severe or vision is almost or completely lost, while facial asymmetry and nasal obstruction often appear to be ignored. Limited medical facilities are partly responsible for the widespread continued adherence to local traditional methods of treatment. Investigations by Edington and Maclean (1965) showed that in a surprising proportion of the community such methods are still popular or even preferred. Thus it is possible that the number of cases which do not reach hospital is not negligible compared with the total recorded incidence.

On possible aetiological factors, Keen et al. (I955) suggest that the habit in the South African Bantu, of taking snuff mixed with various reputedly 


\section{Malignant Diseases of the Paranasal Sinuses in Nigeria}

carcinogenic substances might be a factor although in view of the popularity of the habit among both sexes, he feels that the marked difference in sex incidence (vide supra) is probably due to hormonal factors. The snuff-taking habit varies widely in different regions here, as does the practice of instilling various herbal extracts into the nose as therapeutic or prophylactic measures. As the carcinogenic properties of the ingredients used here have not been studied, it is impossible to estimate the importance, if any, of these practices in the aetiology of paranasal sinus cancer. Chronic upper respiratory tract infection was considered a factor in the aetiology by Ringertz (I938) and later also by Clifford (I96I) who suggested that the mucosal metaplasia which usually follows chronic infection may be the predisposing factor. This view, however, is not shared by Willis (I960). Like many other theories, these are unproved conjectures based on circumstantial, clinical and pathological evidence.

\section{Summary}

One hundred and thirty-six patients with malignant disease of the paranasal sinuses have been seen in the Ear, Nose and Throat Department of the University College Hospital, Ibadan, between I960 and I966. The pattern of the disease is unlike that seen in Europe but resembles that described in other parts of Africa, in which, as noted here, patients usually present for treatment at very advanced stages of the disease. The result is that the available medical and surgical facilities, limited as they are here, do not prove as effective as they might have been under better conditions. Theories of the aetiology up till the present time are based on circumstantial evidence. Prognoses and survival rates so far are dependent not only on the course of the various histopathological types of the disease and their response to available therapy, but also on the attitude of patients towards hospital services and their ability or willingness to attend for follow-up observation and treatment.

\section{Acknowledgments}

We are grateful to Professor Edington of the Department of Pathology for very useful help and advice and to Mrs. Margaret Hendrickse of the Ibadan Cancer Registry for her assistance in compiling the records. We wish also to thank the members of the Medical Illustration Unit for providing the illustrations.

\section{REFERENCES}

Barbosa, J. F. (I96I) Arch. Otolaryng., 73, I 29.

Bras, G., Watler, D. C., and Ashmeade-Dyer, A. (1965) Brit. J. Cancer, 19, 681. Capps, F. C. W. (1950) Proc. roy. Soc. Med., 43, $66_{5}$.

Clemmesen, J. (195I) Acta Un. int. Cancr, 7, Numero special, No. r, p. 24.

ClifFORD, P. (I96I) J. Laryng., 75, 707. 


\section{S. P. Singh and F. D. Martinson}

Dodge, O. G. (I965) Cancer (Philad.), 18, 205.

Edington, G. M., and Maclean, C. M. U. (I965) Brit. J. Cancer, 19, 47 1.

KEEN, P. (I955) S. Afr. med. J., 29, II98.

, de Moor, N. G., Shapiro, M. P., Cooper, R. I.., Cohen, L., and Camphell, J. M. (1955) Brit. J. Cancer, 9, 528.

Linsell, C. A., and Martyn, R. (I962) E. Afr. med. J., 39, 642.

MACBETH, R. (1965) J. Laryng., 79, 592.

Marsden, A. T. H. (I958) Brit. J. Cancer, 12, I6I.

Mattick, W. L., and Streuter, M. A. (I954) Suvgery, 35, 236.

Mel'nikov, R. A. (1960) Prob. Onkol., 3, 80.

OsBorn, D. A., and Winston, P. (I96r) J. Laryng., 75, 387.

Ringertz, N. (1938) Acta oto-laryng. (Stockh.), Suppl. 27, p. I45.

Ross, M. D. (1967) Cent. Afr. J. Med., 13, 107.

Salem, L. E., Zaharia, M., and Travezan, R. (I963) Amer. J. Surg., 106, 826.

Shapiro, M. P., Keen, P., Cohen, L., and De Moor, N. G. (I955) S. Afr. med. J., 29,95 .

Wang, D. Y., Bulbrook, D. R., and Clifford, P. (1966) Lancet, 2, 1342.

Willis, R. A. (r96o) Pathology of tumours. 3rd edition. London.

University College Hospital,

Ibadan,

Nigeria. 